\title{
Prevalence and Risk Factors of Depression among Adult Type 2 Diabetic Patients at Al-Jemaih Diabetic Center, Dongola, Northern State, Sudan, 2019
}

\section{Mohamed Osman Abdelaziz¹, Mohamed Ali Alzain², and Mohammed Abdal- mageed Abdalkhaleg ${ }^{3}$}

${ }^{1}$ Associate Prof. of Internal Medicine.Department of Medicine, Faculty of Medicine \& Health Sciences, University of Dongola, Dongola, PO box 47 Dongola 41111, Sudan

${ }^{2}$ Assistant Prof. Department of Community Medicine, Faculty of Medicine \& Health Sciences, University of Dongola, Dongola, PO box 47 Dongola 41111, Sudan. Department of Public Health, College of Public Health and Health Informatics, University of Hail, KSA. +966 (54) 8398414

${ }^{3}$ Teaching Assistant, Department of Medicine, Faculty of Medicine \& Health Sciences, University of Dongola, Dongola, PO box 47 Dongola 41111, Sudan

Corresponding Author: Mohamed Osman Abdelaziz; Department of Medicine, Faculty of Medicine \& Health Sciences, University of Dongola, PO Box 47, Dongola 41111, Northern State, Sudan Mobile: +249912634357, +24912316669.

email:

dralomda34@gmail.com

Received 7 October 2020

Accepted 17 December 2020

Published 31 December 2020

Production and Hosting by

Knowledge E

(c) Mohamed Osman

Abdelaziz et al. This article is distributed under the terms of the Creative Commons

Attribution License, which permits unrestricted use and redistribution provided that the original author and source are credited.

Editor-in-Chief:

Prof. Mohammad A. M. Ibnouf

\section{Abstract}

Background: Type 2 diabetes and depression are common diseases with bidirectional associations. Depression in diabetics leads to poor adherence to diet and medication, poor glycemic control, reduced quality of life, and increased diabetes-related healthcare expenditure. This study aimed at evaluating diabetic patients with depression to improve the quality of care delivered.

Materials and Methods: An institution-based cross-sectional study was conducted among adult type 2 diabetics at Al-Jemaih Diabetic Center, Dongola, in JulyDecember 2019A standardized pretested questionnaire was used to collect data, and the depression subscale of the Patient Health Questionnaire was used to diagnose depression. Chi-square test and logistic regression were used to analyze the data using the Statistical Package for Social Sciences version 25.0.

Results: Out of the 407 participants, 282 (69.3\%) were females, and more than half were aged between 40 and 59 years. The prevalence of depression among type 2 diabetic patients was $35.6 \%$, ranging from mild $(24.3 \%)$ to moderate $(7.4 \%)$, moderately severe $(2.2 \%)$, and severe depression (1.7\%). The risk factors associated with depression in type 2 diabetes were: combining antidiabetic therapy, long duration of diabetes, family history of psychiatric illness, diabetes-related complications, poor glycemic control, and lack of regular exercise.

Conclusion: More than a third of type 2 diabetics have depression. Screening diabetic patients for depression, establishing a psychiatric unit at the diabetic center, and community-based studies are recommended.

Keywords: diabetes mellitus, depression, Dongola, Northern State

\section{G OPEN ACCESS}




\section{Introduction}

The worldwide number of diabetic patients is rising to pandemic levels [1]. The estimated total number of diabetics was 463 million in 2019 and is expected to increase by $51 \%$ to 700 million cases in 2045 [1]. The global rise of the diabetic population is more likely to affect low-and middle-income countries than the high-income ones. In the Middle East and North African (MENA) region, diabetic estimates will rise by $96 \%$ from 55 million in 2019 to 108 million in 2045 [2]. Sudan was included among the top five countries with the highest prevalence of diabetics in the MENA region in 2019; with a prevalence of $17.9 \%$, a total of 3.7 million cases, and one in every six adults with diabetes [3]. Previous studies demonstrated high prevalence rates of diabetes in North Sudan compared to the other parts of the country $[4,5]$. Moreover, a strong association has been observed between diabetes mellitus (DM) and mental disorders like depression.

Depression is a common mental problem, with a global prevalence of 2-6\% in 2017, affecting more than 264 million people and tends to increase with age [6, 7]. The overall prevalence of depression in Sudan was 3.78\% in 2017 [7]. Depression is common among diabetic patients and is considered a modifiable risk factor for type 2 diabetes mellitus (T2DM) as well as for the progression of diabetes-related complications [8]. Having T2DM more than doubles the risk of depression, and concurrent depression with diabetes is associated with poor adherence to diet and medication, poor glycemic control, reduced quality of life, and increased diabetes-related healthcare expenditure [9]. Therefore, it is important to evaluate diabetic patients for depression to improve the quality of care delivered.

In different studies, two types of validated questionnaires were used to screen diabetic patients for depression: the Patient Health Questionnaire (PHQ-9) and the depression subscale of the Hospital Anxiety and Depression Scale (HADS-D). Both questionnaires have been effectively used in different studies among diabetic patients $[8,10,11] . P H Q$ is a self-administered version of the primary care evaluation of mental disorders (PRIME-MD ${ }^{\circledR}$ ) instrument used for primary care diagnosis of mental disorders, while the PHQ-9 subscale is used for depression [12].

Literature review revealed one study about the prevalence of depression among T2DM patients in Central Sudan (Omdurman) using the HADS questionnaire [13]. Thus far, no study has explored depression among diabetics in the Northern State, Sudan, despite the high prevalence rate of diabetes. Therefore, this study aimed to determine the prevalence and associated factors of depression among adult T2DM patients attending regular follow-up at Al-Jemaih Diabetic Center in Dongola, Northern State, Sudan.

\section{Materials and Methods}

\subsection{Study design, area, and population}

An analytical cross-sectional study was carried out among adults with T2DM attending regular follow-up at the Al-Jemaih Diabetic Center in Dongola, the capital city of the 
Northern State, Sudan, during the period from July 1 to December 30, 2019. The center was initially established in 2003 and then inaugurated after the development as well as renewal by the Al-Jemaih Charity Organization (Kingdom of Saudi Arabia) in April 2018. The center offers medical services at primary, secondary, and tertiary levels to diabetic patients from the whole state. To date, 10,163 diabetic patients including 119 diabetic children have been registered and about 150-250 patients are seen daily.

\subsection{Sample size determination}

The study population included all adult T2DM patients registered at the center and attending routine follow-up during the study period. The minimum sample size was 379, calculated using the following formula:

$$
\frac{z^{2} P(1-P)}{d^{2}},
$$

When the prevalence of depression among DM in Sudan was considered as 44\% [13] with $95 \%$ confidence interval and $5 \%$ precision.

\subsection{Ethical considerations}

Ethical approval was obtained from the Research Ethics Committee at the State Ministry of Health. Informed consent was taken from each participant. Participants with moderate-to-severe depression were recommended to be seen by a psychiatrist for further assessment and management.

\subsection{Data collection}

All adult T2DM patients attending the clinic during the study period were invited to participate. A convenient sampling method was used to select the participants. Those who did not agree to participate, children aged $<18$ years, type 1 diabetic patients, and those who had a recent psychiatric illness or suffered from recent (within one month) loss of a first-degree relative or spouse were excluded from the study. A standardized pretested questionnaire was used to collect data. The questionnaire included personal data, duration, treatment, compliance, follow-up and complications of DM, history of chronic illness or long-term medication, history of tobacco or alcohol use or drug abuse, and family history of psychiatric disease. The participant was considered as having controlled DM if a recent (within three months) glycosylated hemoglobin (HbA1c) level was $<7$ and uncontrolled if the $\mathrm{HbA} 1 \mathrm{c}$ level was $\geq 7$. The PHQ-9 was used as a validated screening tool for detecting depression among diabetic patients [12,14] after it was translated in Arabic and the translation was reviewed by an expert. A pilot sample of 30 respondents was used to measure the reliability of the Arabic-translated PHQ-9 (0.778; 95\% Cl: 0.744-0.809) using Cronbach's alpha test. Two general medical practitioners were trained in data collection to explain to the patients in a simple local language, especially those who were not fluent in Arabic. PHQ-9 scores range from 0 (not at all) to 3 (nearly every day) for the nine diagnostic criteria of depression encountered within 
the last two weeks [15]. While the total score ranges from 0 to 27 [15], the total PHQ-9 score of participants is categorized as following: $0-4=$ no or minimal depression, $5-9=$ mild depression, 10-14 = moderate depression, 15-19 = moderately severe depression, and $20-27$ = severe depression [15]. The participants with score $\geq 5$ were classified as having depression in the further analysis.

\subsection{Data analysis}

Frequency percentage was used to determine the depression prevalence of various degrees of depression, which has been displayed in a histogram. To determine risk factors for depression among diabetic patients, both Chi-square and binary logistic regression were used. Odds ratios (OR) with a confidence interval $(\mathrm{Cl})$ were used to present the logistic regression results. $P$-value $<0.05$ was considered statistically significant. All analyses were done using the Statistical Package for Social sciences (SPSS), version 25.0. (Armonk, New York: IBM Corp, USA).

\section{Results}

A total of 407 diabetic patients were included in the study, of which 282 (69.3\%) were females and $125(30.7 \%)$ males. The study observed that more than half of the respondents were aged between 40 and 59 years, belonged to the Danaglah tribe, and had an education level below the university degree. In addition, more than twothirds $(69.8 \%)$ of the diabetic patients in our study were treated by oral hypoglycemic, and almost one-third (33.2\%) of them had diabetes-related complications. The majority (82.6\%) of the participants had poor glycemic control, and $11.8 \%$ of the respondents had a family history of psychiatric illness, while more than half (54\%) of the study population did not practice regular excise. Chi-square test found that the prevalence of depression among diabetics was significantly increased with long diabetic duration, type of diabetes treatment, presence of complications, family history of psychiatric disease, glycemic control, and exercise status, as shown in Table 1.

The overall prevalence of depression among diabetic patients was $35.6 \%$, ranging from mild to severe forms of depression, whereas the prevalence of major depression (moderate to severe or PHQ-9 score of $\geq 10$ ) was $11.3 \%$, as shown in Figure 1.

Binary logistic regression indicates a positive association between the duration of diabetes and prevalence of depression; whereas diabetic patients with the longer duration ( $\geq 20$ years) were more than three times ( $\mathrm{OR}=3.55 ; 95 \% \mathrm{Cl}: 1.76-7.13$ ) more likely to have depression compared to those with shorter duration ( $<5$ years). Patients treated with a combination of oral hypoglycemic drugs and insulin were more than four times $(\mathrm{OR}=4.26 ; 95 \% \mathrm{Cl}: 1.02-17.86)$ more likely to have depression than those treated only through dietary control. Furthermore, uncontrolled diabetics and those with diabetesrelated complications, family history of psychiatric disease, and those who had never performed physical exercise were almost twice (OR $=1.80 ; 95 \% \mathrm{Cl}: 1.00-3.19),(\mathrm{OR}=$ 1.97; 95\% Cl: $1.07-3.61)$, and (OR $=1.98 ; 95 \% \mathrm{Cl}: 1.07-3.61)$ more likely to have depression compared to other groups, as shown in Table 2. 
TABLE 1: Baseline characteristics of adult type 2 diabetic patients and the prevalence of depression in Al-Jemaih diabetic center, Dongola, Northern State, Sudan, 2019.

\begin{tabular}{|c|c|c|c|c|}
\hline Variables & Total n (\%) & $\begin{array}{c}\text { With depression } \\
\text { n (\%) }\end{array}$ & $\begin{array}{c}\text { Without } \\
\text { depression } \mathbf{n}(\%)\end{array}$ & P-value \\
\hline Total & $407(100)$ & 145 (35.6) & $262(64.4)$ & - \\
\hline \multicolumn{5}{|l|}{ Age } \\
\hline$<40$ years & 49 (12) & 18 (36.7) & 31 (63.3) & 0.260 \\
\hline $40-59$ years & $228(56)$ & $88(38.6)$ & 140 (61.4) & \\
\hline$\geq 60$ years & 130 (31.9) & $39(30.0)$ & $91(70.0)$ & \\
\hline \multicolumn{5}{|l|}{ Gender } \\
\hline Male & $125(30.7)$ & $44(35.2)$ & $81(64.8)$ & 0.905 \\
\hline Female & $282(69.3)$ & $101(35.8)$ & $181(64.2)$ & \\
\hline \multicolumn{5}{|l|}{ Tribes } \\
\hline Danaglah & $223(54.8)$ & 75 (33.6) & $148(66.4)$ & 0.140 \\
\hline Mahass & $50(12.3)$ & $21(42.0)$ & $29(58.0)$ & \\
\hline Halab & $43(10.6)$ & $21(48.8)$ & $22(51.2)$ & \\
\hline Others & $91(22.4)$ & $28(30.8)$ & $63(69.2)$ & \\
\hline \multicolumn{5}{|l|}{ Education } \\
\hline Illiterate & $171(42)$ & 58 (33.9) & $113(66.1)$ & 0.670 \\
\hline Pre-university & $205(50.4)$ & $76(37.1)$ & 129 (62.9) & \\
\hline University \& above & $31(7.6)$ & $11(35.5)$ & $20(64.5)$ & \\
\hline \multicolumn{5}{|l|}{ DM duration } \\
\hline$<5$ years & $124(30.5)$ & $31(25.0)$ & $93(75.0)$ & 0.008 \\
\hline 5-10 years & 125 (30.7) & $46(36.8)$ & $79(63.2)$ & \\
\hline $10-15$ years & $66(16.2)$ & 25 (37.9) & $41(62.1)$ & \\
\hline $15-20$ years & 44 (10.8) & $17(38.6)$ & $27(61.4)$ & \\
\hline$\geq 20$ years & $48(11.8)$ & $26(54.2)$ & $22(45.8)$ & \\
\hline \multicolumn{5}{|l|}{ Type of treatment } \\
\hline Diet only & $12(2.9)$ & $3(25.0)$ & $9(75.0)$ & \\
\hline Oral hypoglycemic & $284(69.8)$ & 87 (30.6) & 197 (69.4) & 0.001 \\
\hline Insulin & $65(16)$ & $28(43.1)$ & 37 (56.9) & \\
\hline $\begin{array}{l}\text { Combined (insulin \& } \\
\text { tablets) }\end{array}$ & $46(11.3)$ & $27(58.7)$ & 19 (41.3) & \\
\hline \multicolumn{5}{|l|}{ DM complications } \\
\hline Yes & 135 (33.2) & 59 (43.7) & 76 (56.3) & 0.017 \\
\hline No & $272(66.8)$ & 86 (31.6) & $186(68.4)$ & \\
\hline \multicolumn{5}{|l|}{$\begin{array}{l}\text { Family history of } \\
\text { psychiatric }\end{array}$} \\
\hline Yes & $48(11.8)$ & $24(50.0)$ & $24(50.0)$ & 0.027 \\
\hline No & $359(88.2)$ & 121 (33.7) & $238(66.3)$ & \\
\hline \multicolumn{5}{|l|}{$\begin{array}{l}\text { Glycemic control } \\
\text { (HbA1c) }\end{array}$} \\
\hline Controlled & 71 (17.4) & $18(25.4)$ & $53(74.6)$ & 0.047 \\
\hline Uncontrolled & $336(82.6)$ & 127 (37.8) & $209(62.2)$ & \\
\hline \multicolumn{5}{|l|}{ Exercise } \\
\hline Yes & 187 (49.9) & $54(28.9)$ & 133 (71.1) & 0.009 \\
\hline No & $220(54.1)$ & $91(41.4)$ & 129 (58.6) & \\
\hline
\end{tabular}




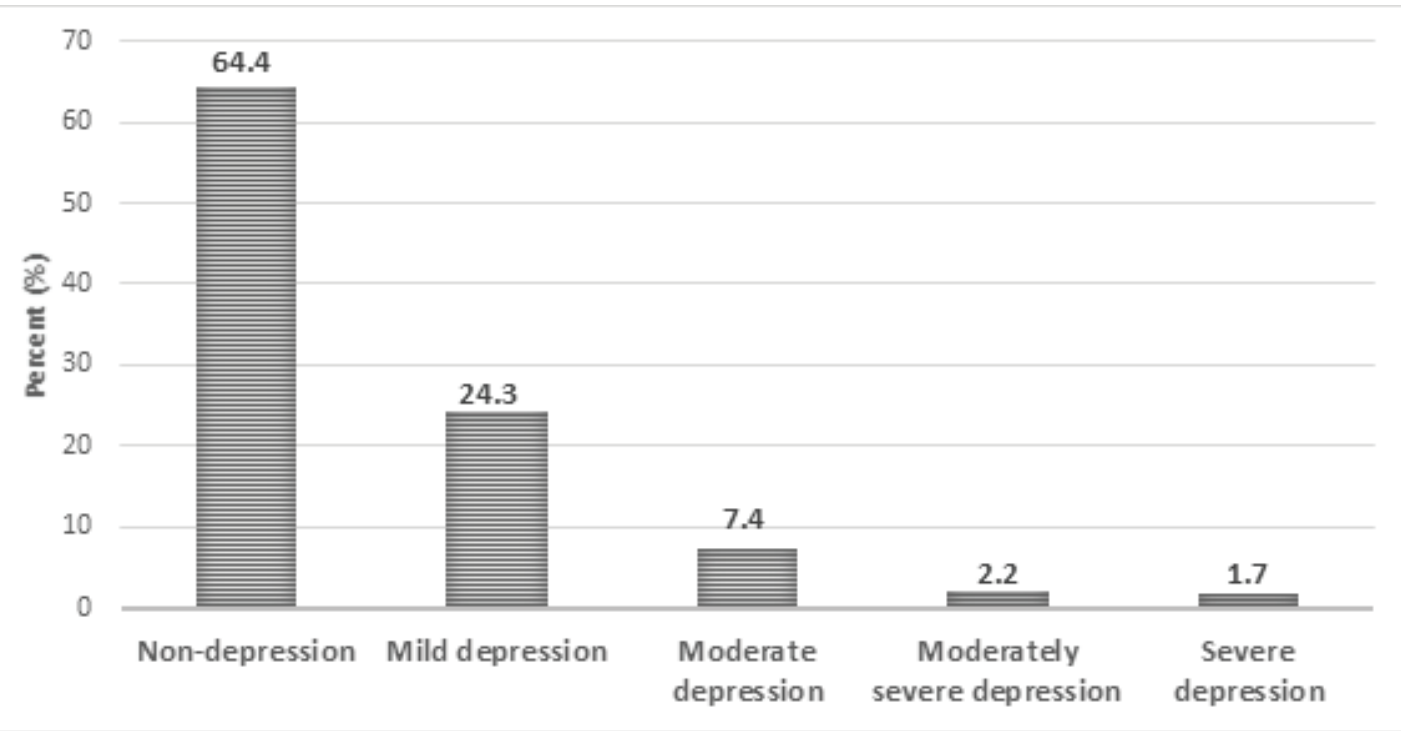

Figure 1: Prevalence of different levels of depression among adult type 2 diabetic patients at the Al-Jemaih Diabetic Center in Dongola, Northern State, Sudan, 2019.

TABLE 2: Factors associated with the prevalence of depression among adult type 2 diabetic patients at the Al-Jemaih Diabetic Center in Dongola, Northern State, Sudan, 2019.

\begin{tabular}{l} 
Variable \\
Duration of DM \\
$<5$ years \\
$5-10$ years \\
10-15 years \\
15-20 years \\
$\geq 20$ years \\
Type of treatment \\
Diet only \\
Oral hypoglycemic \\
Insulin \\
Combined (insulin \& tablets) \\
Glycemic control \\
Yes \\
No \\
DM complication \\
No \\
Yes \\
Family history of psychiatric \\
No \\
Yes \\
Exercise \\
Yes \\
No \\
\hline o
\end{tabular}

\begin{tabular}{|c|}
\hline OR (95\%Cl) \\
\hline Reference \\
\hline 1.75 (1.01-3.01) \\
\hline 1.83 (0.96-3.47) \\
\hline 1.89 (0.91-3.92) \\
\hline 3.55 (1.76-7.13) \\
\hline Reference \\
\hline 1.32 (0.35-5.01) \\
\hline 2.27 (0.56-9.17) \\
\hline 4.26 (1.02-17.86) \\
\hline Reference \\
\hline 1.80 (1.00-3.19) \\
\hline Reference \\
\hline 1.97 (1.07-3.61) \\
\hline Reference \\
\hline $1.07-3.61)$ \\
\hline
\end{tabular}

\begin{tabular}{|c|}
\hline P-value \\
\hline \\
\hline 0.045 \\
\hline 0.065 \\
\hline 0.088 \\
\hline 0.001 \\
\hline 0.679 \\
\hline 0.250 \\
\hline 0.047 \\
\hline 0.049 \\
\hline
\end{tabular}




\section{Discussion}

Depression is common among diabetic patients and affects diabetics in terms of morbidity and mortality. Our study showed a lower prevalence rate of depression compared to a previous study among T2DM in Omdurman Locality, Khartoum State, with a prevalence rate of depression of $44 \%$ [13]. The difference may be partially explained by the different scoring systems; while the study in Khartoum State used the HADS questionnaire, this study used the PHQ-9 score. Besides, our prevalence was also lower than most of the international studies assessing depression in T2DM using PHQ-9 score. A study from Suez Canal University Hospital in Egypt revealed a rate of depression of $69 \%$ in patients with T2DM [16], while a study conducted in Ethiopia showed a depression rate of $54.2 \%$ [17]. Two studies from India showed that the prevalence rates of depression were $41 \%$ and $62 \%$ among T2DM $[18,19]$. The rate of depression in T2DM varies greatly among different sub-Saharan African and Middle Eastern countries, ranging from as low as 15\% in Nigeria and $20 \%$ in Jordan and Oman to as high as 70\% in Iran [20]. The prevalence of major depression was $11.3 \%$, slightly low compared to that of the study from Ethiopia with 13\% [17]. The relatively low prevalence of depression among T2DM in the northern states compared to the national and international studies might be explained by the good family support of diabetic patients and good community awareness about DM as it is a common disease.

This study revealed that the risk factors associated with depression in T2DM were: combined antidiabetic therapy $(\mathrm{OR}=4.26)$, long duration of diabetes $(\mathrm{OR}=3.55)$, family history of psychiatric illness $(O R=1.98)$, diabetes-related complications $(O R=$ 1.97), poor glycemic control $(O R=1.80)$, and lack of regular exercise $(O R=1.74)$. The rates of depression showed no significant difference regarding age, gender, tribe, and educational level. The observed association between combined antidiabetic therapy and depression concurs with an earlier meta-analysis that explored the association between insulin treatment and depression in T2DM; it revealed that insulin therapy was associated with a higher risk of depression [21]. This might be explained by the reluctance of T2DM patients to take insulin as a last option for uncontrolled DM as well as taking multiple medications with increased cost. Other reasons include the long duration of T2DM as most patients start insulin late as well as the presence of diabetesrelated complications and comorbidities. Regarding the duration of T2DM, symptoms of depression tend to increase early after diagnosis and decrease over a few years and then rise with the longer duration of DM, making a j-shaped curve; the rise with the duration of DM may be related to frailty associated with old age and longer duration [22]. Many studies have demonstrated the significant association between depression in T2DM and diabetes-related complications, poor glycemic control, and lack of exercise [23-27]. The family history as a risk factor may be explained by a potential common genetic susceptibility to both T2DM and depression [28], but no study has mentioned a family history of psychiatric illness as a risk factor for depression in T2DM. Interestingly, the depression rate was more common in females than males, but the association was not statistically significant. Most studies considered female gender a significant risk factor for depression in T2DM [22, 25-27]. 
Limitations: The current study had the following limitations: first, it was a crosssectional study, which could not determine the causal factors of depression in T2DM patients; second, it was conducted at an institutional but not at the community level as more depressed diabetics might be seen at the diabetic center indicating possible selection bias. However, this is the first study conducted in the Northern State, a state with high prevalence rates of DM in Sudan, and most likely the second study in Sudan, thus adding new insight to a common problem among diabetics. The study also enrolled a reasonable sample size with a high response rate. Moreover, the cross-sectional study design would give a quick snapshot of the depression rate among diabetic patients in the state for future interventions.

\section{Conclusion}

Our study shows that more than a third of T2DM have depression. Risk factors for depression in T2DM include combined insulin and oral hypoglycemic drug therapy, long duration of T2DM, family history of psychiatric disease, diabetes-related complications, poor glycemic control, and lack of exercise. Screening for depression as well as other psychiatric disorders in all diabetics at the center is necessary and healthcare staff providing diabetic care should be able to diagnose, manage, or refer diabetic patients with depression. The establishment of a psychiatric unit at the center is recommended. Further longitudinal large-scale studies and qualitative studies are recommended for in-depth assessment of depression, anxiety, and other psychiatric disorders among diabetic as well as nondiabetic populations.

\section{Acknowledgements}

The authors would like to express their gratitude to the staff of Al-Jemaih Diabetic Center for their great help in carrying out the study at the center. They are also thankful to the patients who agreed to participate in the study.

\section{Ethical considerations}

Ethical approval was obtained from the Ethics Committee of the State Ministry of Health, Northern State, Sudan.

\section{Competing interests}

The authors declare hereby that there are no conflicts of interest.

\section{Availability of data and materials}

All data are available upon reasonable request. 


\section{Funding}

No funding was received from any governmental or nongovernmental institution.

\section{Authors' Contributions}

Abdelaziz $\mathrm{MO}$ and Alzain MA participated in developing the research concept and design as well as in the training and supervision of the data collectors. Abdakhaleg MA performed data collection. Abdelaziz MO carried out data entry and Alzain MA carried out data analysis using SPSS. All authors participated in writing, editing, and approving the final manuscript.

\section{Disclosure:}

This article or the abstract was not presented in any conference nor it was submitted to any other journal for publication

\section{References}

[1] Huizinga, M. M. and Rothman, R. L. (2006). Addressing the diabetes pandemic: a comprehensive approach. Indian Journal of Medical Research, vol. 124, no. 5, pp. 481-484. Retrieved from https://search.proquest.com/openview/b6814b4ac9d1c29a8fa59e12e6473d10/1?pqorigsite $=$ gscholar\&cbl=37533 (accessed August 1, 2020).

[2] IDF. (2019). IDF Atlas 2019 Fact sheet ( $9^{\text {th }}$ ed.). Retrieved from https://www.diabetesatlas.org/en/ resources/ (accessed August 8, 2020).

[3] IDF. (2019). IDF At/as 2019 Fact sheet: MENA (9 ${ }^{\text {th }}$ ed.). Retrieved from https://www.idf.org/our-network/ regions-members/middle-east-and-north-africa/diabetes-in-mena.html (accessed August 8, 2020).

[4] Elbagir, M., Eltom, M., Elmahadi, E., et al. (1998). A high prevalence of diabetes mellitus and impaired glucose tolerance in the Danagla community in Northern Sudan. Diabetic Medicine, vol. 15, pp. 164-169.

[5] Eltom, M. A., Mohamed, A. H., Elrayah-Eliadarous, H., et al. (2018). Increasing prevalence of type 2 diabetes mellitus and impact of ethnicity in north Sudan. Diabetes Research and Clinical Practice, vol. 136, pp. 93-99. Retrieved from https://doi.org/10.1016/j.diabres.2017.11.034

[6] WHO. (2017). Depression and Other Common Mental Disorders: Global Health Estimates. Geneva: World Health Organization. License: CC BY-NC-SA 3.0 IGO. Retrieved from https://apps.who.int/iris/ bitstream/handle/10665/254610/WHO-MSD-MER-2017.2-eng.pdf (accessed on August 8, 2020).

[7] Ritchie, H. and Roser, M. (2019). Mental Health. Retrieved from https://ourworldindata.org/mental-health (accessed on August 01, 2020).

[8] Thour, A., Das, S., Sehrawat, T., et al. (2015). Depression among patients with diabetes mellitus in North India evaluated using patient health questionnaire-9. Indian Journal of Endocrinology and Metabolism, vol. 19, no. 2, pp. 252-255. doi:10.4103/2230-8210.149318

[9] Lustman, P. J. and Clouse, R. E. (2005). Depression in diabetic patients: the relationship between mood and glycemic control. Journal of Diabetic Complications, vol. 19, no. 2, pp. 113-122. Retrieved from https://doi.org/10.1016/j.jdiacomp.2004.01.002

[10] Reddy, P., Philpot, B., Ford, D., et al. (2010). Identification of depression in diabetes: the efficacy of PHQ-9 and HADS-D. British Journal of General Practice, vol. 60, no. 575, pp. e239-e245. Retrieved from https://doi.org/10.3399/bjgp10X502128

[11] van Steenbergen-Weijenburg, K. M., de Vroege, L., Ploeger, R. R., et al. (2010). Validation of the PHQ-9 as a screening instrument for depression in diabetes patients in specialized outpatient clinics. BMC Health Services Research, vol. 10, p. 235. Retrieved from https://doi.org/10.1186/1472-6963-10-235

[12] Kroenke, K., Spitzer, R. L., and Williams, J. B. (2001). The PHQ-9: validity of a brief depression severity measure. Journal of General Internal Medicine, vol. 16, no. 9, pp. 606-613. Retrieved from https: //doi.org/10.1046/j.1525-1497.2001.016009606.x 
[13] Mirghani, H. O., Mohammed, O. S., and Saadallah, A. M. (2014). Prevalence of depression among Sudanese patients with type 2 diabetes mellitus. Sudan Journal of Medical Sciences, vol. 9, no. 3, pp. 151-155. Retrieved from https://www.ajol.info/index.php/sjms/article/view/114285

[14] Udedi, M., Muula, A. S., Stewart, R. C., et al. (2019). The validity of the patient health Questionnaire-9 to screen for depression in patients with type-2 diabetes mellitus in non-communicable diseases clinics in Malawi. BMC Psychiatry, vol. 19, p. 81. Retrieved from https://doi.org/10.1186/s12888-019-2062-2

[15] Kroenke, K., Spitzer, R. L., and Williams, J. B. (2001). The PHQ-9: validity of a brief depression severity measure. Journal of General Internal Medicine, vol. 16, no. 9, pp. 606-613. Retrieved from https: //doi.org/10.1046/j.1525-1497.2001.016009606.x

[16] Ismail, M. F. S., Fares, M. M., and Abd-Alrhman, A. G. (2019). Prevalence of depression and predictors of glycemic control among type 2 diabetes mellitus patients at family medicine clinic, Suez Canal University Hospital Egypt. World Family Medicine, vol. 17, no. 2, pp. 4-13. Retrieved from https://pdfs. semanticscholar.org/4173/a0e90cd797877e0205929048e919593c7d2d.pdf

[17] Habtewold, T. D., Radie, Y. T., and Sharew, N. T. (2015). Prevalence of depression among type 2 diabetic outpatients in Black Lion Specialized Hospital, Addis Ababa, Ethiopia. Depression Research and Treatment, article ID 184902. Retrieved from https://doi.org/10.1155/2015/184902

[18] Thour, A., Das, S., Sehrawat, T., et al. (2015). Depression among patients with diabetes mellitus in North India evaluated using patient health questionnaire-9. Indian Journal of Endocrinology and Metabolism, vol. 19, no. 2, pp. 252-255. Retrieved from https://dx.doi.org/10.4103\{\%]2F2230-8210.149318

[19] Nagabhirava, G., Umate, M., Nimkar, S., et al. (2017). Depression and anxiety as comorbid disorders in patients with type ii diabetes. International Journal of Medical Science and Public Health, vol. 6, no. 3, pp. 544-548. doi:10.5455/ijmsph.2017.0956304102016

[20] Mendenhall, E., Norris, S. A., Shidhaye, R., et al. (2014). Depression and type 2 diabetes in low- and middle-income countries: a systematic review. Diabetes Research and Clinical Practice, vol. 103, no. 2, pp. 276-285. Retrieved from https://doi.org/10.1016/j.diabres.2014.01.001

[21] Bai, X., Liu, Z., Li, Z., et al. (2018). The association between insulin therapy and depression in patients with type 2 diabetes mellitus: a meta-analysis. BMJ Open, vol. 8, no. 11, p. e020062. Retrieved from http://dx.doi.org/10.1136/bmjopen-2017-020062

[22] Darwish, L., Beroncal, E., Sison, M. V., et al. (2018). Depression in people with type 2 diabetes: current perspectives. Diabetes, Metabolic Syndrome and Obesity: Targets and Therapy, vol. 11, pp. 333-343. Retrieved from https://dx.doi.org/10.2147\{\%\}2FDMSO.S106797

[23] Azeze, G. A., Adema, B. G., Adella, G. A., et al. (2020). Factors associated with untreated depression among type 2 diabetic patients at Halaba Kulito Hospital, South Ethiopia: a cross-sectional study. Diabetes, Metabolic Syndrome and Obesity: Targets and Therapy, vol. 13, pp. 2189-2198. Retrieved from https://dx.doi.org/10.2147\{\%\}2FDMSO.S255360

[24] Arambwela, M. H., Somasundaram, N. P., Jayasekara, H. B. P. R., et al. (2019). Prevalence of depression and associated risk factors among patients with type 2 diabetes attending the diabetic clinic at the tertiary care hospital in Sri Lanka: a descriptive study. Psychiatry Journal, article ID 7468363. Retrieved from https://doi.org/10.1155/2019/7468363

[25] Lloyed, C. E., Nouwen, A., Sartorious, N., et al. (2018). Prevalence and correlates of depressive disorders in people with Type 2 diabetes: results from the International Prevalence and Treatment of Diabetes and Depression (INTERPRET -DD ) study, a collaborative study carried out in 14 countries. Diabetes Medicine. Retrieved from https://doi.org/10.1111/dme.13611

[26] Andreoulakis, E., Hyphantis, T., Kandylis, D., et al. (2012). Depression in diabetes mellitus: a comprehensive review. Hippokratia, vol. 16, no. 3, pp. 205-214.

[27] World Health Organization. (2017). Addressing comorbidity between mental disorders and major noncommunicable diseases. Retrieved from https:/www.euro.who.int/en/publications/abstracts/ addressing-comorbidity-between-mental-disorders-and-major-noncommunicable-diseases-2017 (accessed on August 07, 2020).

[28] Andreoulakis, E., Hyphantis, T., Kandylis, D., et al. (2012). Depression in diabetes mellitus: a comprehensive review. Hippokratia, vol. 16, no. 3, pp. 205-214. Retrieved from https://www.ncbi.nlm. nih.gov/pmc/articles/PMC3738724/pdf/hippokratia-16-205.pdf 